\title{
Numerical study on thermal performance of a solar air collector with fins and baffles attached over the absorber plate
}

\author{
Faris Aissaoui $^{1 *}$, Abdelmoumene H. Benmachiche ${ }^{2}$, Abdelhafid Brima ${ }^{1}$, Yousef Belloufi ${ }^{1}$, Moussa Belkhiri ${ }^{1}$ \\ ${ }^{1}$ Laboratoire de Génie Mécanique, Universitêe Biskra, B.P.145 R.P. Biskra 07000, Algeria \\ ${ }^{2}$ Department of Mechanics, University of Biskra, B.P.145 R.P. Biskra 07000, Algeria \\ Email: techno_fares@yahoo.fr
}

\begin{abstract}
In this study, a mathematical model is developed for simulating the influence of fins and baffles on the thermal performance behavior of single pass solar air collector system working in forced convection. Due to the lack of theoretical work in the case of single pass solar air heaters having artificial roughness, we have proposed a theoretical model which consists of dividing the collector into several differential elements along the panel. This model is based on a numerical solution of energy equations in each component of collector. The results obtained from the present work and results of others researches are in good agreement. Using energy analysis, influence of parameters such as width of baffles, distance between baffles, length of air heater and number of fins are presented. The obtained results would be useful to select the most efficient and design parameters.
\end{abstract}

Keywords: Baffles, Efficiency, Fins, Solar Air Collector.

\section{INTRODUCTION}

Since the petrol crisis, attention is drawn to the various sources of alternative energy, including: renewable energy geothermal energy [1], solar energy, wind energy etc. Solar system is the energy which the sun provides by its radiation directly or diffusely through the atmosphere. Solar energy transformed into heat is usually reorganized as one of the most effective ways to exploit solar energy. It has found many applications in the field of heating, drying, cold production, etc. [2-5]. Several types of air collectors were constructed and tested throughout the world. The main objective is to collect the maximum amount of solar energy at minimum use materials and cost $[6,7]$.

To increase the efficiency of solar air collectors, the heat transfer coefficient between the absorber plate and air stream should be improved, one of the most common methods to increase the heat transfer coefficient using the turbulence promoters in the form of artificial roughness on the absorber plate. In order to improve the performance of solar air heaters, different methods have been suggested to increase the rate of heat transfer between air stream and absorber plate. According to many researches, the performance of solar air collectors can be improved by utilizing corrugated surfaces $[8,9]$, employed artificial roughness in the air duct [10-12], attaching fins [13-18] and fins and baffles [19-22]. These ways mentioned are usually introduced as some of most promising kinds of the performance enhancement techniques. They play double aspect role in promoting heat transfer to the air flow: i) they make the turbulent flow near the hot plate $[23,24]$; ii) they extend the path of the air flow [25, 26].

A number of studies have investigated theoretically for different air heaters designs by applying the heat balance equations in order to compute the temperature distributions in each of their components [27-31]. Mohammadi and Sobzpooshani[29] investigated the influence of fins and baffles attached over the absorber plate on the performance of the upward type single pass solar air collector the problem was treated and solved theoretically under steady state conditions. Yeh [32] investigated theoretically the effect of internal re cycle on the collector efficiency in upward-type flat-plate solar air collectors with fins attached. The results of their work illustrated that the improvement in solar air collector efficiency increase with increasing reflux ratio, especially for operating at lower flow rate of air with higher inlet air temperature. Moreover, the performance in the device operated with internal recycle overcomes that in the same-size device operated with external recycle. However, the study did not take into consideration the effect on fins number height and fin arrangement. Bahrehmand et al.[33]developed a mathematical model for simulating the thermal behavior of single and two glass cover solar air heater systems worked in forced convection flow. Results of their work showed that, the systems with fin and thin metal sheet are more efficient than other studied systems from the 
energy and exergy efficiency standpoints. Another work was presented by Bahrehmand and Amri[28] which studied single and two-glass cover solar air collectors with natural convection flow. Their goal was to show the effect of longitudinal fins, as well as the depth and length variations of the channel on energy and exergy performances of the air heaters. They noticed that the devices with two-glass are more efficient than a single glass solar air collector. Mohammadi and Sabzpooshani[34] appraising the possibility of enhancing thermal performance of an upward-type single pass solar air collector by utilizing fins and baffles over the absorber plate as well as applying external recycle device simultaneously under various parametric conditions. Their results discouraged the utilization fins and baffles over the absorber plate under applying external recycling operation at high mass flow rates and recycle ratios. Sabzpooshani et al. [35]studied the exergetic performance of a baffled type solar air collector has been evaluated theoretically. A detailed parametric study was done to investigate the effect of variation of fin and baffle parameters, number of glass covers, bottom insulation thickness and inlet air temperature at different mass flow rates on the exergy efficiency. The results indicated that attaching fins and baffles at low mass flow rates can lead to noticeable enhancement of the exergy efficiency. The results revealed that the trend of variation of the energy and exergy efficiencies are not the same and the exergy efficiency is the chief criterion for performance evaluation. Ho et al.[36] examined the performance of a double pass solar air heater with fins and baffles attached under influence of external recycling operation. They made a comparison between the performances of several designs such as the single-pass, double pass with recycle, fined double-pass with recycle, and fined plus baffled double-pass with recycle. The results disclosed that the increment of recycle ratio leads to enhance the efficiency. Moreover, the lowest amount of efficiency improvement and highest amount of power consumption is attained for the fined plus baffled double-pass design under external recycle. They also introduced the recycle ratio of 0.5 as optimum value for the fined plus baffled double-pass solar air heater.

Experimental and theoretical investigation are presented by Aissaoui et al. [27] to simulate the local heat transfer coefficient in flat plate single pass solar air collector working in forced convection. A comparison results between a theoretical prediction and the measured temperatures were conducted through different solar radiation intensity.

The review of bibliographic studies indicates that the previous studies used complicated model. On this account, the prime aim of this study is to propose an approach model which consists of dividing the air solar collector into several differential elements along the collector. Then, to the second aim of this research work is to investigate the effect of pertinent geometric and thermo-physics parameters on solar air collectors with fins and baffles attached. In other words, the performance of different solar air collectors' systems using the first and second laws of thermodynamics is investigated.

\section{MATHIMATICAL MODEL}

In this study, solar air collectors are investigated, single pass solar air collector with and without fins and baffles attached over the absorber plate.
The mathematical model is developed according to an energy balance equations performed on each component of the solar air collector systems. Figures 1 and 2 show schematic diagram of single pass upward type solar air heater with fins and baffles attached over the absorber plate.

In order to simplify the mathematical model, the following assumptions are made:

- $\quad$ The system operates under steady state conditions.

- The air temperature changes only in the direction of the air flow.

- $\quad$ Heat transfer through the glass covers and absorber plate is 1-D and in the direction of perpendicular to the air flow.

- The lateral walls heat losses are neglected due to their small amount.

- The fins thickness is negligible compared to their length.

In order to determine temperature distribution in each collector component, including air flow, energy flux balance equations are applied to a differential length control volume, parallel to flow direction,lying on top side on the glass cover, and in the bottom side onthe absorberplate, as shown in Fig. 3 .

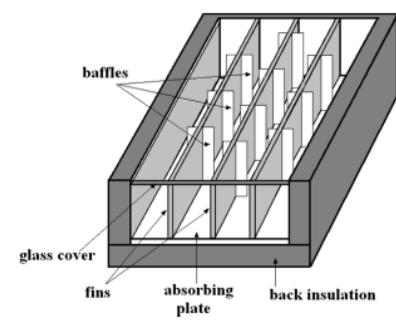

Figure 1. Schematic diagram of the studied model, solar air heater with fins and baffles attached over the absorber plate[29].

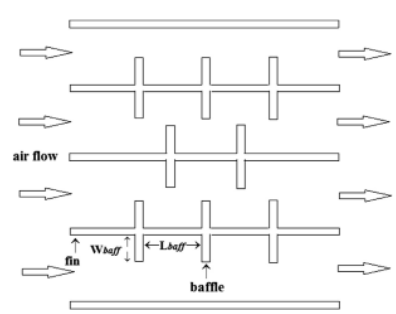

Figure 2. Top viewof the solar air collector studied[29].

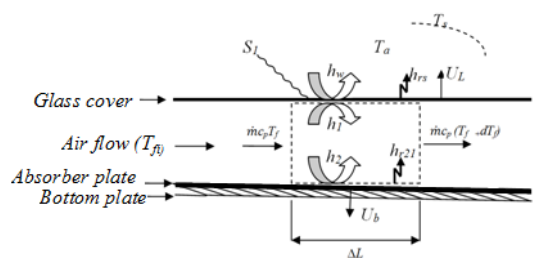

Figure 3. Schematic representation of heat transfer in the different collector components

\subsection{Energy balance equations}

The following energy balance equations are written for various air heater components in each control volume:

For the glass cover 
$\mathrm{S}_{1}+h_{r 21}\left(T_{2}-T_{1}\right)+h_{1}\left(T_{f}-T_{1}\right)=U_{L}\left(T_{1}-T_{a}\right)$

For the air flow

$\dot{m} C_{p} \frac{d T_{f}}{W d x}=\varphi h_{2}\left(T_{2}-T_{f}\right)-h_{1}\left(T_{f}-T_{1}\right)$

For the absorber plate

$\varphi h_{2}\left(T_{2}-T_{f}\right)+h_{r 21}\left(T_{2}-T_{1}\right)+U_{b}\left(T_{2}-T_{a}\right)=S_{2}$

where $\varphi$ is dimensionless coefficient defined as follows:

$\varphi=1+\frac{A_{\text {fin }}}{A_{p}-A_{\text {finb }}} \eta_{\text {fin }}+\frac{A_{\text {baff }}}{A_{p}-A_{\text {finb }}} \eta_{\text {baff }}$

$\eta_{\text {ailet }}$ is the fin efficiency and can be obtained as

$\eta_{\text {fin }}=\frac{\tanh \left(m H_{\text {fin }}\right)}{m H_{\text {fin }}}$

where

$m=\left(\frac{2 h_{3}\left(L+t_{f i n}\right)}{K_{f i n} L t_{f i n}}\right)^{\frac{1}{2}}$

$\eta_{\text {baff }}$ is the efficiency which may be obtained from the following emperical equation[19]:

$\eta_{\text {baff }}=\left(\frac{W_{\text {baff }}}{D_{h}}\right)^{0.0518}\left(\frac{L}{L_{b a f f}}\right)^{-0.2247}$

It should be mentioned that when there are no fins and baffles attached to the absorber plate, $\varphi$ is equal to 1 .

\subsection{Estimation of heat transfer coefficients}

Effect of wind. In order to identify the external convection coefficient, the relationship is used[37]:

$h_{w}=5.7+3.8 \mathrm{~V}$

Convective heat transfer coefficient between the absorber and the air flow. In order to determine the convective heat transfer coefficient inside in the case of rectangular channels for laminar ( $\operatorname{Re} \leq 2300)$ and turbulent $(\operatorname{Re} \geq 2300)$ forced convection flow is estimated by using the Eqs.(9) and (10), respectively[38, 39].

$N u=\frac{h_{3} D_{\mathrm{h}}}{k_{f}}=4.4+\frac{0.00398\left(0.7 R e D_{\mathrm{h}} / L\right)^{1.66}}{1+0.0114\left(0.7 \operatorname{Re} D_{\mathrm{h}} / L\right)^{1.12}}$

$N u=\frac{h D_{h}}{K}=0.0158 R e^{0.8}$

$D_{h}=\frac{4 A}{P}=\frac{2\left(\left(W d-n H_{f i n} t_{f i n}\right)\right.}{(W+d)+n\left(H_{f i n}+t_{f i n}\right)}$

Heat transfer by radiation. The absorbed solar radiation absorber is:

$S_{1}=\tau \cdot \alpha_{1} \cdot I$
Radiative transfer coefficient between the absorber plate and the sky. The radiative transfer coefficient between the glass cover and the sky can be given by the formula:

$h_{r S}=\frac{\sigma \varepsilon_{1}\left(T_{1}+T_{S}\right)\left(T_{1}^{2}+T_{S}^{2}\right)\left(T_{1}-T_{S}\right)}{\left(T_{1}-T_{a}\right)}$

The temperature of the sky is given by the formula[40]:

$T_{S}=0.0552 T a^{1,5}$

Radiative transfer coefficient between the cover glass and the absorber plate. The radiation heat transfer coefficient from the absorber plate to glass cover is estimated as follow:

$h_{r 21}=\frac{\sigma\left(T_{1}^{2}+T_{2}^{2}\right)\left(T_{1}+T_{2}\right)}{\frac{1}{\varepsilon_{2}}+\frac{1}{\varepsilon_{2}}-1}$

Coefficient of thermal losses toward the rear of the solar air collector. The coefficient of thermal losses toward the rear of the air solar collector is given by:

$U_{b}=\frac{1}{i=\sum_{1}^{n} \frac{X_{b i}}{k_{b i}}+\frac{1}{h_{w}}}$

Coefficient of thermal losses to the front of the collector. The coefficient of thermal losses to the front of the solar collector air is given by:

$U_{L}=h_{w}+h_{r s}$

\subsection{Properties of air flow}

Thermal properties of air flow are considered to be variables according the flow expressions[41], where :

$C_{p}=999.2+0.143 T_{f}+1.61 \times 10^{-4} T_{f}^{2}-6.7581 \times 10^{-8} T_{f}^{3}$

$K=0.0244+0.6773 \times 10^{-4} T_{f}(19)$

$v=0.1284 \times 10^{-4}+0.00105 \times 10^{-4} T_{f}$

$\rho=\frac{353.44}{T_{f}+273}$

where $T_{f}$ is the fluid temperature evaluated in Celsius.

\subsection{Numerical calculations and solution method}

Table 1. Detailed specifications of the solar air heaters.

\begin{tabular}{llll}
\hline $\mathrm{I}=700$ and & $\mathrm{t}_{\mathrm{fin}}=0.001 \mathrm{~m}$ & $\mathrm{~T}_{\mathrm{fi}}=\mathrm{T}_{\mathrm{a}}$ & $\mathrm{T}_{\mathrm{a}}=290 \mathrm{~K}$ \\
$900 \mathrm{~W} / \mathrm{m}^{2}$ & & & \\
$\varepsilon_{1}=0.9$ & $\varepsilon_{2}=0.94$ & $\alpha_{1}=0.05$ & $\alpha_{2}=0.94$ \\
$\tau=09$ & $\sigma=5.67 \times 10^{-8}$ & $\mathrm{~V}=1 \mathrm{~m} / \mathrm{s}$ & \\
\hline
\end{tabular}

Numerical calculations have been carried out to calculate the energy efficiency for different solar air collector systems with given operating conditions. In order to obtain the results numerically, proper codes are developed in FORTRAN using the fixed parameters tabulated in Table 1.

In each control volume, the finite difference method is applied to approximate the air temperature gradient as follows: 
$\frac{d T_{f}}{d x} \approx \frac{T_{f, i}-T_{f, i-1}}{\Delta x}$

The $3 \times 3$ system of equations is written in matrix form for unknown $T_{l}, T_{2}$ and $T_{f}$ and a linear system is solved, because the coefficient matrix is the unknown function of temperature, an iterative scheme is performed. The procedure of the solution in each section is repeated throughout the length of the manifold.

And in the present program, the coefficients for the both upper and lower surfaces of channel were assumed equal; $\mathrm{h}_{1}=\mathrm{h}_{2}$.

The useful heat transferred to air can be written in terms of the mean fluid and inlet temperatures as follows:

$Q=\Gamma\left(T_{f}-T_{f,-1}\right)$

$\Gamma=m C_{p} /(W \Delta x)$

$[A]=$

$\left[\begin{array}{ccc}\left(h_{1}+h_{r 21}+U_{l}\right) & -h_{1} & -h_{r 21} \\ h_{1} & -\left(\varphi h_{2}+h_{1}+\Gamma\right) & \varphi h_{2} \\ -h_{r 21} & -\varphi h_{2} & \left(\varphi h_{2}+h_{r 21}+U_{b}\right)\end{array}\right]$

,$[T]=\left[\begin{array}{c}T_{1} \\ T_{f} \\ T_{2}\end{array}\right]$ And $[B]=\left[\begin{array}{c}S_{1}+U_{L} T_{a} \\ -\Gamma T_{f, i-1} \\ S_{2}+U_{b} T_{a}\end{array}\right]$.

Gauss elimination is used to calculate the unknown temperatures $T_{1}, T_{2}$ and $T_{f}$.

The elements of the matrix [A] contain radiation heat transfer coefficients which depend on the unknown temperatures; an iterative process based on substitution technique was the carried out in each control volume.

\section{VALIDATION WITH LITERATURE}

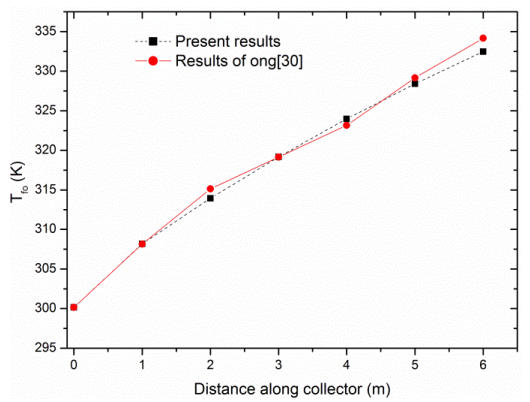

Figure 4. Outlet temperature as a function of distance along the solar air heater without fins

To confirm the reliability of our theoretical study, we compared the results of our code with previous results. The results obtained and published by Ong [30]are used to exanimate the validity of the proposed model from the single pass solar air collector without fins. Figure 4 shows the outlet air temperature as a function of distance along collector, the results reflect good consistency with those of Ong[30].

To approve the stability and robustness of our mathematical and numerical approach to both, we conducted another validation for the solar air collector plane with fins and baffles attached on the absorber plate with the numerical results of Mohamedi et al. [29] in terms of thermal efficiency different procedures. Due to the absence of the experimental study for single pass solar air collector with fins and baffles attached over the absorber plate that is why we compared the obtained results in terms of efficiency with the previous study [29]for the same configuration, system properties and operating conditions and $\mathrm{I}=700 \mathrm{~W} / \mathrm{m}^{2}$. The comparison results are shown in figure 5. It is clear that the present results are in favorable agreement with the results obtained by Mohamedi et al.

We have performed a second validation with the results of Mohamedi et al. [29] in thermal efficiency and outlet air temperature at different procedures to approve the stability and robustness of our numerical approach. Table 2. Shows the effect of changing of fins and baffles (distance between baffles and baffles depth) for mass flow rate $\dot{m}=0.03 \mathrm{Kg} / \mathrm{s}, \dot{m}$ $=0.05 \mathrm{Kg} / \mathrm{s}$ on the outlet air temperature and thermal efficiency. The results obtained were compared with the results of Mohamedi et al.[29] for the same configurations, system proprieties and operating conditions for $\mathrm{I}=700$ $\mathrm{W} / \mathrm{m}^{2}$.The comparison results are presented in the table 2 . It is clear that the present results are in favorable agreement with the results of previous work.

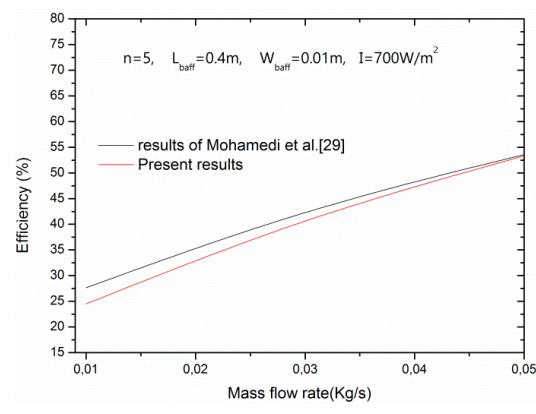

Figure 5. Comparisons of the thermal efficiency of present air collector with fins and baffles attached over the absorber plate with theoretical studied by Mohamedi et al. [29].

\section{RESULTS AND DISCUSSIONS}

The energy gain $\left(Q_{u}\right)$, thermal efficiency ( $\eta$ ) and outlet temperature $\left(T_{f o}\right)$ for mass flow rates of $\dot{m}=0.01 \mathrm{Kg} / \mathrm{s}, \dot{m}=0.03 \mathrm{Kg} / \mathrm{s}$ and $\dot{m}=0.05 \mathrm{Kg} / \mathrm{s}$; various number of fins and baffles parameters and for $\mathrm{I}=900 \mathrm{~W} / \mathrm{m}^{2}$ are tabulated in table 3 . It is noted that $Q_{u}$ and $\eta$ increase with increasing the mass flow rate, number of fins and baffles parameters. At constant number of fins and baffles parameters, the outlet temperature also increases with increasing the number of fins and baffles parameters and decrease with increasing the mass flow rate. The same result is obtained with increasing the number of fins at constant baffles parameters. Furthermore, raising the number of fins at constant baffles parameters and increasing the width of baffles at constant number of fins, the outlet air temperature, energy gain and efficiency increases, and this influence reduces with increasing the parameters. On the other hand, the distance between baffles at constant number of fins results in enhancing the energy gain and efficiency and this effect increases with reducing the distances between baffles.

Absorber plate, glass cover and air flow temperatures are plotted in figures $(6,7)$ with and without fins and baffles attached over the absorber plate at $\mathrm{I}=700 \mathrm{~W} / \mathrm{m}^{2}, \dot{m}=0.02$ $\mathrm{Kg} / \mathrm{s}$. In all results, it was observed that the absorber plate 
exhibited the highest temperature. It was seen also that small temperature differences between air flow and the cover glass of the order of $2 \mathrm{~K}$, it could be obtained if the solar air collector contains fins and baffles.

Figures $(8,9)$ include variations of the outlet temperature for different width of baffles and distances between baffles with mass flow rate for $\mathrm{I}=900 \mathrm{~W} / \mathrm{m}^{2}$. In all results, it can be noted that the increase in mass flow rate lead to decrease in the outlet temperature. It is evident that the outlet temperature increases with increasing parameters $\mathrm{W}_{\text {baff }}$ and $\mathrm{L}$ baff, in comparison with the solar air collector without fins due to increase in the rate heat transfer from the absorber plate to air stream.

Figure10illustratesvariations of the outlet temperature of solar air collector as a function of mass flow rate by changing number of fins for $\mathrm{I}=900 \mathrm{~W} / \mathrm{m}^{2}$, it is found that the effect of increasing the number of fins more than 7 is not remarkable, the obtained results from figure. 9xreveals that with increasing the number of fins, the outlet temperature increases.

According the figures, it can be noted that the increasing in the mass flow rate leads to decrease in the outlet temperature.

Figure 11 shows the effect of Nusselt number on outlet temperature of single pass solar air collector without fins for various length of collector at solar intensity $\mathrm{I}=900 \mathrm{~W} / \mathrm{m}^{2}$, the curves indicate for $\mathrm{L}=2, \mathrm{~L}=3$ and $\mathrm{L}=5, \mathrm{~L}=7$ and $\mathrm{L}=9$, at Nusselt number ranging from 5 to 15 with solar intensity of $\mathrm{I}=900 \mathrm{~W} / \mathrm{m}^{2}$, the outlet air temperature dropped from $339.62 \mathrm{~K}$ to $305.36,340.78 \mathrm{~K}$ to $310.76 \mathrm{~K}, 361.42 \mathrm{~K}$ to $320.56 \mathrm{~K}, 370.68 \mathrm{~K}$ to $328.97 \mathrm{~K}, 375.68 \mathrm{~K}$ to $335.81 \mathrm{~K}$ respectively.

Table 2. Comparison of the present results for single pass solar air without and with fins and baffles attached over the absorber plate with the results of Mohamedi et al.[29]for $\mathrm{I}=700 \mathrm{~W} / \mathrm{m}^{2}$.

\begin{tabular}{|c|c|c|c|c|c|c|c|c|c|c|c|c|}
\hline \multirow[t]{3}{*}{$\mathrm{n}$} & \multirow[t]{3}{*}{$\mathrm{L}_{\text {baff }}$} & \multirow[t]{3}{*}{$\mathrm{W}_{\text {baff }}$} & \multicolumn{5}{|c|}{$\dot{\mathrm{m}}=0.03(\mathrm{Kg} / \mathrm{s})$} & \multicolumn{5}{|c|}{$\dot{\mathrm{m}}=0.05(\mathrm{Kg} / \mathrm{s})$} \\
\hline & & & $\mathrm{T}_{\mathrm{fo}}(\mathrm{k})$ & & $\eta \%$ & & & $\mathrm{~T}_{\mathrm{fo}}$ & & $\eta \%$ & & \\
\hline & & & $\begin{array}{l}\text { Present } \\
\text { results }\end{array}$ & $\begin{array}{l}\mathrm{T}_{\mathrm{fo}}(\mathrm{k}) \operatorname{Ref} \\
{[7]}\end{array}$ & $\begin{array}{l}\text { Present } \\
\text { results }\end{array}$ & $\begin{array}{l}\eta \% \\
\text { Ref[7] }\end{array}$ & Error\% & $\begin{array}{l}\text { Present } \\
\text { results }\end{array}$ & $\begin{array}{l}\mathrm{T}_{\mathrm{fo}}(\mathrm{k}) \operatorname{Ref} \\
{[7]}\end{array}$ & $\begin{array}{l}\text { Present } \\
\text { results }\end{array}$ & $\begin{array}{l}\eta \% \\
\operatorname{Ref}[7]\end{array}$ & Error\% \\
\hline 0 & & & 306.07 & 306.03 & 34.67 & 34.62 & 0.14 & 302.59 & 303.15 & 45.28 & 47.31 & 4.29 \\
\hline \multirow[t]{12}{*}{5} & 0.40 & 0.01 & 309.97 & 309.20 & 43.09 & 41.47 & 3.92 & 304.90 & 304.82 & 53.58 & 53.30 & 0.52 \\
\hline & & 0.03 & 312.03 & 310.66 & 47.53 & 44.62 & 6.52 & 306.08 & 306.20 & 57.84 & 58.27 & 0.74 \\
\hline & & 0.05 & 313.64 & 311.94 & 51.01 & 47.39 & 7.64 & 306.96 & 306.96 & 60.99 & 60.99 & 0.01 \\
\hline & 0.20 & 0.01 & 310.71 & 309.70 & 44.68 & 42.56 & 4.99 & 305.33 & 305.62 & 55.14 & 56.18 & 1.85 \\
\hline & & 0.03 & 313.63 & 311.94 & 51.00 & 47.39 & 7.62 & 306.96 & 306.96 & 60.98 & 60.99 & 0.01 \\
\hline & & 0.05 & 315.60 & 313.71 & 55.24 & 51.21 & 7.87 & 307.96 & 307.95 & 64.61 & 64.56 & 0.08 \\
\hline & 0.10 & 0.01 & 311.81 & 310.50 & 47.07 & 44.29 & 6.28 & 305.96 & 306.11 & 57.42 & 57.94 & 0.90 \\
\hline & & 0.03 & 315.59 & 313.71 & 55.23 & 51.21 & 7.85 & 307.96 & 307.95 & 64.60 & 64.56 & 0.07 \\
\hline & & 0.05 & 317.68 & 315.89 & 59.73 & 55.92 & 6.81 & 308.97 & 309.10 & 68.22 & 68.70 & 0.70 \\
\hline & 0.05 & 0.01 & 313.35 & 311.72 & 50.39 & 46.91 & 7.43 & 306.81 & 306.83 & 60.45 & 60.52 & 0.12 \\
\hline & & 0.03 & 317.68 & 315.89 & 59.72 & 55.92 & 6.79 & 308.96 & 309.10 & 68.21 & 68.70 & 0.72 \\
\hline & & 0.05 & 319.58 & 318.22 & 63.83 & 60.96 & 4.71 & 309.83 & 310.26 & 71.32 & 72.85 & 2.10 \\
\hline \multirow[t]{11}{*}{7} & 0.40 & 0.01 & 311.18 & 309.64 & 45.69 & 42.43 & 7.69 & 305.57 & 305.59 & 56.00 & 56.11 & 0.19 \\
\hline & & 0.03 & 313.56 & 311.57 & 50.84 & 46.59 & 9.13 & 306.90 & 306.74 & 60.78 & 60.28 & 0.83 \\
\hline & & 0.05 & 315.28 & 313.15 & 54.55 & 50.01 & 9.07 & 307.79 & 307.65 & 63.99 & 63.53 & 0.73 \\
\hline & 0.20 & 0.01 & 312.06 & 310.32 & 47.60 & 43.90 & 8.43 & 306.07 & 306.00 & 57.81 & 57.61 & 0.34 \\
\hline & & 0.03 & 315.28 & 313.15 & 54.54 & 50.01 & 9.05 & 307.79 & 307.65 & 63.98 & 63.53 & 0.71 \\
\hline & & 0.05 & 317.22 & 315.19 & 58.73 & 54.42 & 7.93 & 308.74 & 308.75 & 67.41 & 67.48 & 0.11 \\
\hline & 0.10 & 0.01 & 313.33 & 311.37 & 50.33 & 46.17 & 9.02 & 306.77 & 306.63 & 60.32 & 59.87 & 0.76 \\
\hline & & 0.03 & 317.21 & 315.19 & 58.72 & 54.42 & 7.91 & 308.74 & 308.75 & 67.40 & 67.48 & 0.12 \\
\hline & & 0.05 & 319.10 & 317.49 & 62.79 & 59.37 & 5.76 & 309.61 & 309.90 & 70.54 & 71.65 & 1.55 \\
\hline & 0.05 & 0.01 & 314.99 & 312.88 & 53.92 & 49.43 & 9.08 & 307.64 & 307.50 & 63.45 & 62.99 & 0.73 \\
\hline & & 0.03 & 319.09 & 317.49 & 62.78 & 59.37 & 5.74 & 309.61 & 309.90 & 70.53 & 71.65 & 1.56 \\
\hline
\end{tabular}

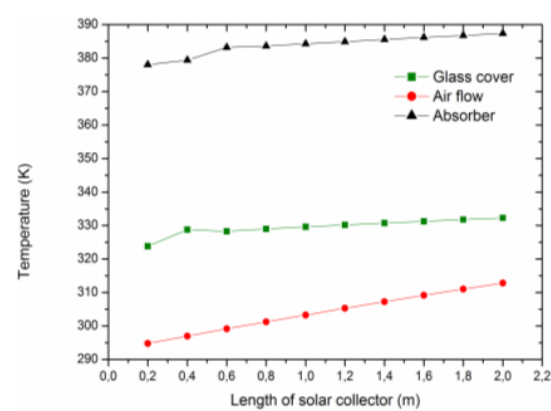

Figure 6. Outlet temperature distribution along the solar air collector without fins attached

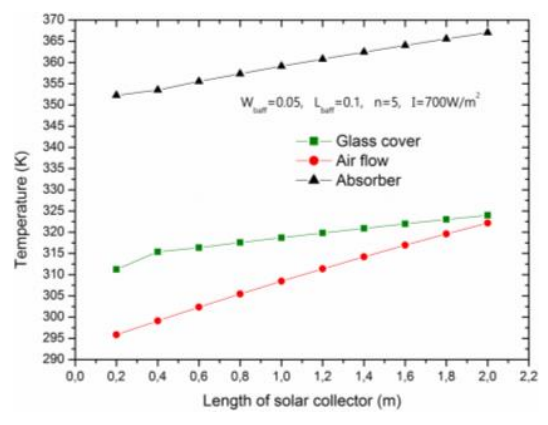

Figure 7. Outlet temperature distribution along solar collector with fins and baffles attached 
Table 3. Energy gain $\left(Q_{u}\right)$, thermal efficiency $(\eta)$ and outlet air temperature $\left(T_{f_{0}}\right)$ for $I=900 \mathrm{~W} / \mathrm{m}^{2}$

\begin{tabular}{|c|c|c|c|c|c|c|c|c|c|c|c|}
\hline \multirow[t]{2}{*}{$\mathrm{n}$} & \multirow[t]{2}{*}{$L_{\text {baff }}$} & \multirow[t]{2}{*}{$\mathrm{W}_{\text {baff }}$} & \multicolumn{3}{|c|}{$\dot{\mathrm{m}}=0.01(\mathrm{Kg} / \mathrm{s})$} & \multicolumn{3}{|c|}{$\dot{m}=0.03 \mathrm{Kg} / \mathrm{s}$} & \multicolumn{3}{|c|}{$\dot{m}=0.05 \mathrm{Kg} / \mathrm{s}$} \\
\hline & & & $\mathrm{T}_{\mathrm{fo}}(\mathrm{k})$ & $\mathrm{Q}_{\mathrm{u}}$ & $\eta \%$ & $\mathrm{~T}_{\mathrm{fo}}(\mathrm{k})$ & $\mathrm{Qu}_{\mathrm{u}}$ & $\eta \%$ & $\mathrm{~T}_{\mathrm{fo}}(\mathrm{k})$ & $\mathrm{Q}_{\mathrm{u}}$ & $\eta \%$ \\
\hline 0 & & & 329.86 & 401.82 & 22.32 & 312.57 & 0682.55 & 37.92 & 308.17 & 0915.78 & 50.88 \\
\hline \multirow[t]{12}{*}{5} & 0.40 & 0.01 & 331.83 & 421.66 & 23.43 & 313.54 & 0711.96 & 39.55 & 308.80 & 0947.49 & 52.64 \\
\hline & & 0.03 & 335.69 & 460.57 & 25.59 & 315.42 & 0768.64 & 42.70 & 309.97 & 1006.58 & 55.92 \\
\hline & & 0.05 & 339.18 & 495.70 & 27.54 & 317.07 & 0818.71 & 45.48 & 310.96 & 1056.60 & 58.70 \\
\hline & 0.20 & 0.01 & 333.15 & 434.99 & 24.17 & 314.19 & 0731.53 & 40.64 & 309.21 & 0968.18 & 53.79 \\
\hline & & 0.03 & 339.18 & 495.71 & 27.54 & 317.07 & 0818.71 & 45.48 & 310.96 & 1056.62 & 58.70 \\
\hline & & 0.05 & 344.16 & 545.90 & 30.33 & 319.38 & 0888.40 & 49.36 & 312.28 & 1122.93 & 62.39 \\
\hline & 0.10 & 0.01 & 335.28 & 456.43 & 25.36 & 315.22 & 0762.68 & 42.37 & 309.85 & 1000.48 & 55.58 \\
\hline & & 0.03 & 344.16 & 545.91 & 30.33 & 319.38 & 0888.42 & 49.36 & 312.28 & 1122.95 & 62.39 \\
\hline & & 0.05 & 350.58 & 610.65 & 33.93 & 322.25 & 0975.16 & 54.18 & 313.82 & 1200.42 & 66.69 \\
\hline & 0.05 & 0.01 & 338.56 & 489.52 & 27.20 & 316.78 & 0809.97 & 45.00 & 310.79 & 1048.02 & 58.22 \\
\hline & & 0.03 & 350.58 & 610.67 & 33.93 & 322.25 & 0975.18 & 54.18 & 313.82 & 1200.44 & 66.69 \\
\hline & & 0.05 & 357.82 & 683.59 & 37.98 & 325.34 & 1068.77 & 59.38 & 315.36 & 1278.19 & 71.01 \\
\hline \multirow[t]{12}{*}{7} & 0.40 & 0.01 & 333.90 & 442.52 & 24.58 & 314.12 & 0729.29 & 40.52 & 309.17 & 0965.93 & 53.66 \\
\hline & & 0.03 & 339.07 & 494.57 & 27.48 & 316.60 & 0804.26 & 44.68 & 310.68 & 1042.50 & 57.92 \\
\hline & & 0.05 & 343.46 & 538.87 & 29.94 & 318.66 & 0866.55 & 48.14 & 311.88 & 1102.67 & 61.26 \\
\hline & 0.20 & 0.01 & 335.71 & 460.72 & 25.60 & 314.99 & 0755.72 & 41.98 & 309.71 & 0993.45 & 55.19 \\
\hline & & 0.03 & 343.46 & 538.88 & 29.94 & 318.66 & 0866.56 & 48.14 & 311.88 & 1102.69 & 61.26 \\
\hline & & 0.05 & 349.32 & 597.92 & 33.22 & 321.33 & 0947.42 & 52.63 & 313.34 & 1176.37 & 65.35 \\
\hline & 0.10 & 0.01 & 338.53 & 489.19 & 27.18 & 316.34 & 0796.60 & 44.26 & 310.53 & 1034.88 & 57.49 \\
\hline & & 0.03 & 349.32 & 597.94 & 33.22 & 321.33 & 0947.44 & 52.64 & 313.34 & 1176.38 & 65.35 \\
\hline & & 0.05 & 356.20 & 667.29 & 37.07 & 324.37 & 1039.30 & 57.74 & 314.89 & 1254.44 & 69.69 \\
\hline & 0.05 & 0.01 & 342.70 & 531.26 & 29.51 & 318.30 & 0855.94 & 47.55 & 311.68 & 1092.65 & 60.70 \\
\hline & & 0.03 & 356.20 & 667.31 & 37.07 & 324.37 & 1039.32 & 57.74 & 314.89 & 1254.45 & 69.69 \\
\hline & & 0.05 & 363.14 & 737.28 & 40.96 & 327.32 & 1128.67 & 62.70 & 316.29 & 1325.17 & 73.62 \\
\hline
\end{tabular}

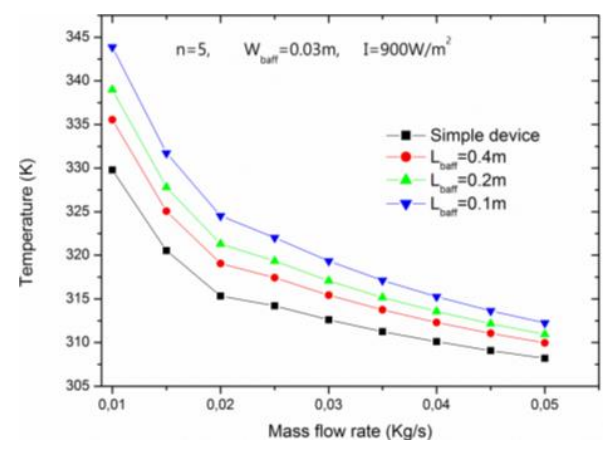

Figure 8. Variations of outlet air temperatures as a function of mass flow rate for various lengths of baffles

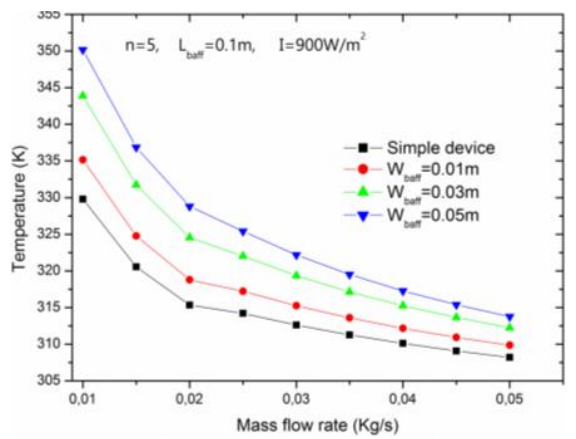

Figure 9. Variations of outlet air temperatures as a function of mass flow rate for various widths of baffles

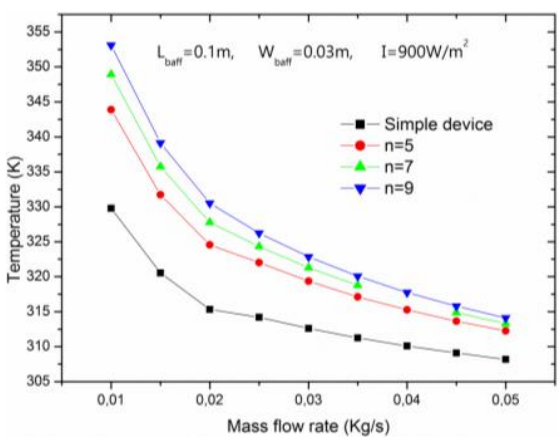

Figure 10. Variations of outlet air temperatures as a function of mass flow rate for various numbers of fins and baffles

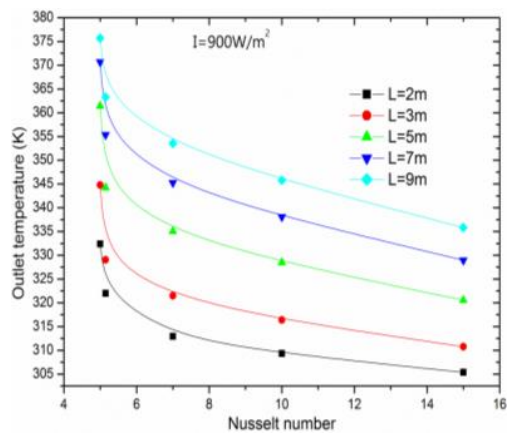

Figure 11. Outlet temperature of single pass solar air collector without fins for different Nusselt number and collector length at $\mathrm{I}=900 \mathrm{~W} / \mathrm{m}^{2}$ 


\section{CONCLUSIONS}

In this research work, the thermal performance of single pass solar air collector with and without fins and baffles attached over the absorber plate has been carried out theoretically. We have proposed a mathematical model which consists of dividing the collector into several differential elements along the solar air collector. Thermal balance equations are then applied over each element in conjunction. From the FORTRAN numerical code, we have computed the temperature profiles of the glass cover, air flow and absorber plate. On the basis of the energy analysis, with attaching fins and baffles and increasing the number of fins as well as baffles density (increasing baffle width and decreasing distance between baffles), the energy efficiency continuously enhances with the increasing mass flow rate. The results of the proposed approach agree closely with values of previous work researches.

\section{RFERENCES}

[1] Belloufi Y., Brima A., Atmani R., Moummi N., Aissaoui F. (2016). Theoretical and experimental study of air refresh by a geothermal heat exchanger air/ground, LARHYSS Journal ISSN 1112-3680, Vol. 25, pp. 121-137.

[2] Buonomo B., Manca O., Nardini S., Romano P. (2013). Thermal and fluid dynamic analysis of solar chimney building systems, International Journal of Heat \& Technology, Vol. 31, No. 2, pp. 119-126.

[3] Coppi M., Quintino A., Salata F. (2011). Fluid dynamic feasibility study of solar chimney in residential buildings, Int. J. Heat Technol, Vol. 29, pp. $1-5$.

[4] Rouag A., Benchabane A., Labed A., Belhadj K., Boultif N. (2016). Applicability of a solar adsorption cooling machine in semiarid regions: proposal of supplementary cooler using earth-water heat exchanger, International Journal of Heat and Technology, Vol. 34, No. 2, pp. 281-286. DOI: 10.18280/ijht.340218

[5] Rouag A., Benchabane A., Labed A., Boultif N. (2016). Thermal design of air cooled condenser of a solar adsorption refrigerator, Journal of Applied Engineering Science \& Technology, Vol. 2, No. 1, pp. 23-29.

[6] Varun G., Saini R.P., Singal S.K. (2007). A review on roughness geometry used in solar air heaters, Solar Energy, Vol. 81, No. 11, pp. 1340-1350. DOI: 10.1016/j.solener.2007.01.017

[7] Wazed M.A., Nukman Y., Islam M.T. (2010). Design and fabrication of a cost effective solar air heater for Bangladesh, Applied Energy, Vol. 87, No. 10, pp. 3030-3036. DOI: 10.1016/j.apenergy.2010.02.014

[8] Karim M.A., Hawlader M.N.A. (2006). Performance investigation of flat plate, $\mathrm{v}$-corrugated and finned air collectors, Energy, Vol. 31, No. 4, pp. 452-470. DOI: 10.1016/j.energy.2005.03.007

[9] Lin W., Gao W., Liu T. (2006). A parametric study on the thermal performance of cross-corrugated solar air collectors, Applied Thermal Engineering, Vol. 26, No. 10, pp. 1043-105. DOI 10.1016/j.applthermaleng.2005.10.005
[10] Karwa R., Chitoshiya G. (2013). Performance study of solar air heater having v-down discrete ribs on â absorber plate, Energy, Vol. 55, pp. 939-955. DOI: 10.1016/j.energy.2013.03.068

[11] Saini R.P., Verma J. (2008). Heat transfer and friction factor correlations for a duct having dimple-shape artificial roughness for solar air heaters, Energy, Vol. 33, No. 8, pp. 1277-1287. DOI: 10.1016/j.energy.2008.02.017

[12] Tanda G. (2011). Performance of solar air heater ducts with different types of ribs on the absorber plate, Energy, Vol. 36, pp. 6651-6660. DOI: 10.1016/i.energy.2011.08.043

[13] El-Sebaii A.A., Aboul-Enein S.M., Ramadan R.I., Shalaby S.M., Moharram B.M. (2011). Thermal performance investigation of double pass-finned plate solar air heater, Applied Energy, Vol. 88, No. 5, pp. 1727-1739. DOI :10.1016/j.apenergy.2010.11.017

[14] Lertsatitthanakorn C., Khasee N., Atthajariyakul S., Soponronnarit S., Therdyothin A., Suzuki R.O. (2008). Performance analysis of a double-pass thermoelectric solar air collector, Solar Energy Materials and Solar Cells, Vol. 92, No. 9, pp. 1105-1109. DOI: 10.1016/j.solmat.2008.03.018

[15] Naphon P. (2005). On the performance and entropy generation of the double-pass solar air heater with longitudinal fins, Renewable Energy, Vol. 30, No. 9, pp. 1345-1357. DOI: 10.1016/j.renene.2004.10.014

[16] Ozgen F., Esen M., Esen H. (2009). Experimental investigation of thermal performance of a double-flow solar air heater having aluminium cans, Renewable Energy, Vol. 34, No. 11, pp. 2391-2398. DOI: 10.1016/i.renene.2009.03.029

[17] Yeh H.M., Ho C.D. (2009). Effect of external recycle on the performances of flat-plate solar air heaters with internal fins attached, Renewable Energy, Vol. 34, No. 5, pp. 1340-1347. DOI: 10.1016/j.renene.2008.09.005

[18] Yeh H.M., Ho C.D., Hou J.Z. (2002). Collector efficiency of double-flow solar air heaters with fins attached, Energy, Vol. 27, No. 8, pp. 715-727. DOI: 10.1016/S0360-5442(02)00010-5

[19] Ho C.D., Yeh H.M., Cheng T.W., Chen T.C., Wang R.C. (2009). The influences of recycle on performance of baffled double-pass flat-plate solar air heaters with internal fins attached, Applied Energy, Vol. 86, No. 9, pp. 1470-1478. DOI: $10.1016 /$ j.apenergy.2008.12.013

[20] Ho-Ming Y. (1992). Theory of baffled solar air heaters, Energy, Vol. 17, No. 7, pp. 697-702. DOI: 10.1016/0360-5442(92)90077-D

[21] Yeh H.M. (1994). Energy balances for upward-type baffled solar air heaters, Energy, Vol. 19, No. 9, pp. 919-924. DOI: 10.1016/0360-5442(94)90076-0

[22] Yeh H.M., Ho C.D., Lin C.Y. (2000). Effect of collector aspect ratio on the collector efficiency of upward type baffled solar air heaters, Energy Conversion and Management, Vol. 41, No. 9, pp. 971981. DOI: $10.1016 / \mathrm{S} 0196-8904(99) 00148-X$

[23] Gao W., Lin W., Liu T., Xia C. (2007). Analytical and experimental studies on the thermal performance of cross-corrugated and flat-plate solar air heaters, Applied Energy, Vol. 84, No. 4, pp. 425-441. DOI: 10.1016/j.apenergy.2010.11.017

[24] Tonui J.K., Tripanagnostopoulos Y. (2007). Improved $\mathrm{PV} / \mathrm{T}$ solar collectors with heat extraction by forced or 
natural air circulation, Renewable Energy, Vol. 32, No. 4, pp. 623-637. DOI: 10.1016/j.renene.2006.03.006

[25] Mohamad A.A. (1997). High efficiency solar air heater, Solar Energy, Vol. 60, No. 2, pp. 71-76. DOI: 10.1016/S0038-092X(96)00163-6

[26] Verma S.K., Prasad B.N. (2000). Investigation for the optimal thermohydraulic performance of artificially roughened solar air heaters, Renewable Energy, Vol. 20, No. 1, pp. 19-36. DOI: 10.1016/S09601481(99)00081-6

[27] Aissaoui F., Benmachiche A.H., Brima A., Bahloul D., Belloufi Y. (2016). Experimental and theoretical analysis on thermal performance of the flat plate solar air collector, International Journal of Heat and Technology, Vol. 34, No. 2, pp. 213-220. DOI: 10.18280/ijht.340209

[28] Bahrehmand D., Ameri M. (2015). Energy and exergy analysis of different solar air collector systems with natural convection, Renewable Energy, Vol. 74, pp. 357-368. DOI: 10.1016/j.renene.2014.08.028

[29] Mohammadi K., Sabzpooshani M. (2013). Comprehensive performance evaluation and parametric studies of single pass solar air heater with fins and baffles attached over the absorber plate, Energy, Vol. 57, pp. 741-750. DOI: $\underline{10.1016 / \text { j.energy.2013.05.016 }}$

[30] Ong K.S. (1995). Thermal performance of solar air heaters: mathematical model and solution procedure, Solar Energy, Vol. 55, No. 2, pp. 93-109. DOI: $\underline{10.1016 / 0038-092 X(95) 00021-I}$

[31] Sopian K., Alghoul M.A., Alfegi E.M., Sulaiman M.Y., Musa E.A. (2009). Evaluation of thermal efficiency of double-pass solar collector with porousâ€"nonporous media, Renewable Energy, Vol. 34, pp. 640-645. DOI: 10.1016/j.renene.2008.05.027

[32] Yeh H.M. (2012). Upward-type flat-plate solar air heaters attached with fins and operated by an internal recycling for improved performance, Journal of the Taiwan Institute of Chemical Engineers, Vol. 43, No. 2, pp. 235-240.

[33] Bahrehmand D., Ameri M., Gholampour M. (2015). Energy and exergy analysis of different solar air collector systems with forced convection, Renewable Energy, Vol. 83, pp. 1119-1130.

[34] Mohammadi K., Sabzpooshani M. (2014). Appraising the performance of a baffled solar air heater with external recycle, Energy Conversion and Management, Vol. 88, pp. 239-250.

[35] Sabzpooshani M., Mohammadi K., Khorasanizadeh H. (2014). Exergetic performance evaluation of a single pass baffled solar air heater, Energy, Vol. 64, pp. 697706.

[36] Ho C.D., Chang H., Wang R.C., Lin C.S. (2012). Performance improvement of a double-pass solar air heater with fins and baffles under recycling operation, Applied Energy, Vol. 100, pp. 155-163.

[37] McAdams W.H. (1954). Heat transmission.

[38] Bazilian M.D., Prasad D. (2002). Modelling of a photovoltaic heat recovery system and its role in a design decision support tool for building professionals, Renewable Energy, Vol. 27, No. 1, pp. 57-68. DOI: $\underline{\text { 10.1016/S0960-1481(01)00165-3 }}$

[39] Duffie J.A., Beckman W.A. (1980). Solar Engineering of Thermal Processes, John Willey \& Sons, New York.

[40] Swinbank W.C. (1963). Long-wave radiation from clear skies, Quarterly Journal of the Royal Meteorological Society, Vol. 89, No. 381, pp. 339-348. DOI: $10.1002 / \mathrm{qj} .49708938105$

[41] Tiwari G.N. (2002). Solar energy: fundamentals, design, modelling and applications, Alpha Science Int'l Ltd., 2002.

\section{NOMENCLATURE}

$T_{1}$

$T_{2}$

$T_{f}$

$T_{a}$

$T_{s}$

I

$h_{1}$

$h_{2}$

$h_{r 21}$

$h_{r s}$

$h_{w}$

$C_{p}$

$K_{f}$

$k_{b i}$

$U_{L}$

$U_{b}$

$\dot{m}$

V

$\mathrm{Nu}$

Re

W

$L$

$X_{b i}$

$d$

$D_{h}$

A

$P$

$Q$

$H_{\text {fin }}$

$t_{\text {fin }}$

\section{Greeks symbols}

$\varepsilon_{1} \quad$ Emissivity of glass cover

$\varepsilon_{2} \quad$ Emissivity of absorber surface

$\alpha_{1} \quad$ Absorptivity of absorber plate

$\alpha_{2} \quad$ Absorptivity of cover glass

$\tau \quad$ Transmissivity

$\rho \quad$ Density of air stream $\left(\mathrm{Kg} / \mathrm{m}^{2}\right)$

$\sigma \quad$ Stefan -Boltzmann constant

$\mu \quad$ Dynamic viscosity of air stream $\left(\mathrm{Kgm}^{-1} \mathrm{~S}-{ }^{1}\right)$ 